\title{
3DBody Software Experimental Platform for Course of Sports Anatomy
}

\author{
https://doi.org/10.3991/ijet.v12.i09.7482 \\ Yujia Ren \\ Hunan First Normal University, Changsha, China \\ Xia Jiang \\ Wuhan Sports University, Wuhan, China \\ Siyuan Tang $(\bowtie)$ \\ Central South University, Changsha, China \\ $1186224696 @$ qq. com
}

\begin{abstract}
Sports anatomy is one of the important basic subjects of sports colleges and universities. As multimedia network technology increasingly matures and is popularized, it becomes an irresistible trend to transform the traditional teaching mode of sports anatomy into multimedia network teaching mode. Thus, a new-type experimental platform based on action-orientated approach and provided with MVC framework and 3DBody experimental software is put forward in this paper, and it is analyzed and interpreted from the aspects of curriculum design principle and function module of the experimental platform, teaching design model of the experimental platform, and teaching and learning methods. These findings indicate the new-type experimental platform designed in this paper is highly spoken of by students for helping improve students' practical skill and ability and arouse students' subjective initiative in learning.
\end{abstract}

Keywords-Action-orientated approach, multimedia teaching software, 3DBody, MVC

\section{Introduction}

With the development and maturation of software technology, teaching software is not limited to helping recite words or remember formula any more. Instead, it also starts entering school and becomes a teaching aid. Traditional teaching software is still used for presenting definitions, videos and pictures only, which still adheres to the dull duck-stuffing type of teaching of traditional classroom. Hence, the main development direction of teaching experimental software platform is to facilitate interaction between teachers and students and arouse students' learning initiative [1].

The aim of action-orientated teaching method [2] is to motive students to act, so that students can take the initiative to think in learning activities, fully integrate theo- 
retical knowledge into practice, and consolidate and learn new theoretical knowledge to achieve the teaching objectives. The key to this teaching method is transfer the leading role from teacher to students in teaching process. Thus, teacher should act to assist, guide and evaluate students, while students should give their subjective initiative into full play. By applying action-orientated approach in the new-type experimental platform software to integrate interactivity, partialness and network intelligence, the common intelligent teaching environment of network software can be satisfied, student-teacher interaction similar to that in real classroom can be realized, the leading role of students can be maintained, and practice can be integrated into theoretical teaching.

\section{State of the art}

In modern times when information and computer technology develops rapidly, multimedia experimental platform has entered schools long ago, and been applied in classroom teaching of various courses. Brenton et al. [3] developed 3D teaching resources in the teaching practice of anatomy, including a three-dimensional model of the adult brachial plexus, which is a network of nerves extending from the neck down to the shoulder, arm, hand, and fingers; and a piece of online courseware which will teach the embryological development of the brachial plexus. The three-dimensional model of the adult brachial plexus will be incorporated into existing didactic classroom teaching under the supervision of an anatomy teacher. The delivery method will be the WebSET framework, which is a collaborative environment that allows a teacher to manipulate $3 \mathrm{D}$ models over the $\mathrm{Web}$ in real time while providing explanation and help to students. Good teaching effect has been achieved. Stirling et al. [4] made a comparison of the use of an enriched multimedia eBook with traditional methods for teaching the gross anatomy of the heart and great vessels. The results show that as initial interaction with the multimedia content together with active experimentation in the anatomy lab was conducted, students were found to get improved in the final test. The obtained data supports the role of eBook technology in modern anatomy curriculum as a useful adjunct to traditional methods. Saltarelli et al. [5] built an experimental software system called "Anatomy and Physiology Revealed" (APR), which is a model-based multimedia simulation tool that uses high-resolution pictures to construct a prosected cadaver, and also provides animations showing the function of specific anatomical structures. Researches show that this software is helpful to improve students' cognition degree of knowledge. Zhou [6] created animations during experimental curriculum, and applied the animations in the multimedia teaching courseware of sports anatomy to provide dynamic materials. On this basis, Zhou set a PBL problem base about motor system, guided students to create animations of motion activity, and applied PBL in the teaching of the course. The results show that most teachers and students were highly satisfied with it. Sports anatomy is one of the basic theoretical courses of students of sports specialty, which is of great importance to the follow-up teaching of theoretical courses and technical courses. Since this course relates to a lot of knowledge points and numerous different sports movements, 
and is relatively dull, less theoretical, and difficult to memorize, most students regard it to be difficult. The learning of sports anatomy requires observation via experimental curriculum, and linking with various movements and the growth and development law of human body. So far, many improvement measures have been developed for experimental teaching of sports anatomy. One of the measures is to apply multimedia technology, but there are still defects. For example, there are many multimedia teaching software with different functions available, so that students often have to download various software, which is time-consuming and resource-consuming [6]. Secondly, most multimedia courseware of sports anatomy are designed to contain static pictures as image material. In the course of sports anatomy, motor system is the focal point, which covers the articular movement forms, muscular working conditions, and motion analysis. Thus, it is not easy to interpret this part with static pictures. Instead, it is possible that static pictures will increase the barriers for students to comprehend the knowledge points.

Hence, this paper is intended to put forward a new-type experimental software platform based on action-orientated approach and provided with MVC framework and 3D virtual technology. It has the function of multimedia input and output, can help teachers and students finish all teaching activities with this software, creatively introduces 3DBody (a three-dimensional anatomy virtual software), and introduces the action-orientated approach into software design. Via this platform, students can take the initiative to make analysis and study knowledge via practice. It provides a good idea and direction for the teaching of sports medicine in future.

\section{Model analysis}

The new-type experimental platform put forward in this paper is integrated with action-orientated approach and 3DBody teaching software, and based on MVC platform and JAVA language. The following is about the theoretical knowledge applied in software construction.

\subsection{Action-orientated learning theory}

According to the action-orientated learning theory, students should be regarded as the center, students' behaviors should be based on, and measures should be taken to arouse students' enthusiasm for learning and subjective initiative to the largest extent, give full play to students' creativity, and train students' ability of problem solving [7]. Thus, a teaching process can be completed in 6 steps, as below (Fig. 1): theoretical knowledge learning, study plan making, action decision implementation, field implementation, control flow check, and result evaluation.

\subsection{MVC framework}

MVC is short for Model, view and controller, which is a code organization form in which data, interface and business logic are written separately [8]. Usually, a model, 
in correspondence with certain database table, contains encapsulated type of data and logics related to data, such as data reading, data updating, data insertion, and data deletion. View refers to user interface, is related to model, and mainly provides the function of data display. View is also used to interact with users, and receives the data input by users and transfers the data to the controller for processing. Controller is the business logic layer, which calls model data according to the data input by users to realize the functions needed by users, such as data validation check, data operation and logical function realization. The mode of writing data, interface and business logic separately can not only facilitate developer in code partitioning at the time of developing software or websites and tester in module testing and accurately identifying problems, but also facilitate modification of interface or data or business logic separately in the follow-up process of website or software maintenance, without influence on other layers. Thus, the workload and maintenance cost both can be reduced. Please see Fig. 2 for the frame diagram of MVC.

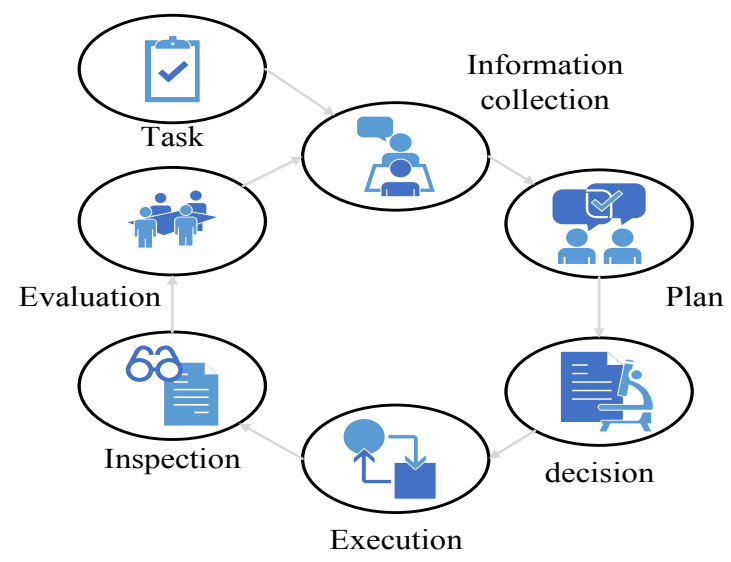

Fig. 1. Structure diagram of action-orientated theory

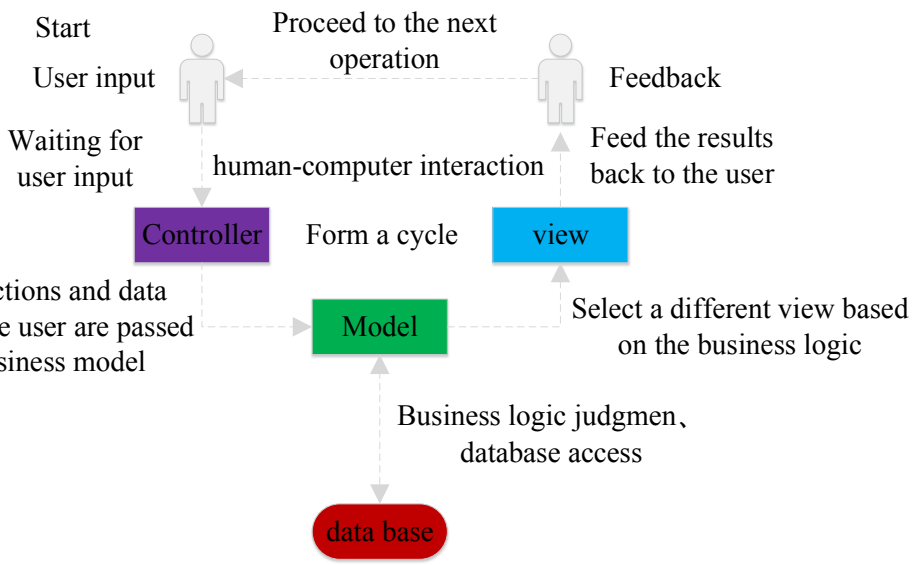

Fig. 2. Frame diagram of MVC 


\subsection{DBody three-dimensional interaction anatomy software}

3DBody is a three-dimensional interaction anatomy software. It provides two sets of fully 3D digital model (including a man and a woman). Each set of model consists of more than 5000 body structures, which provides the most complete anatomical data so far. The models cover all human body systems, covering systematic anatomy and topographic anatomy, and providing literal explanation, bone landmark diagram, muscle action animations, origins and terminations of muscles, acupuncture points, trigger point, sectional anatomy, and so on [9]. 3DBody, as an advanced software at home and abroad, provides detailed data and powerful operating functions. It is easy to obtain the opportunity of anatomizing human body by operating this software. 3DBody series software is a comprehensive and accurate three-dimensional anatomical database based on CTMRI scanning data of human body. This series software gathers high-precision three-dimensional digital anatomical models of all systems and organs of human body [10]. The contents of the software cover systematic anatomy, topographic anatomy and other contents. Fig. 3 shows screenshot of an interface of 3DBody.

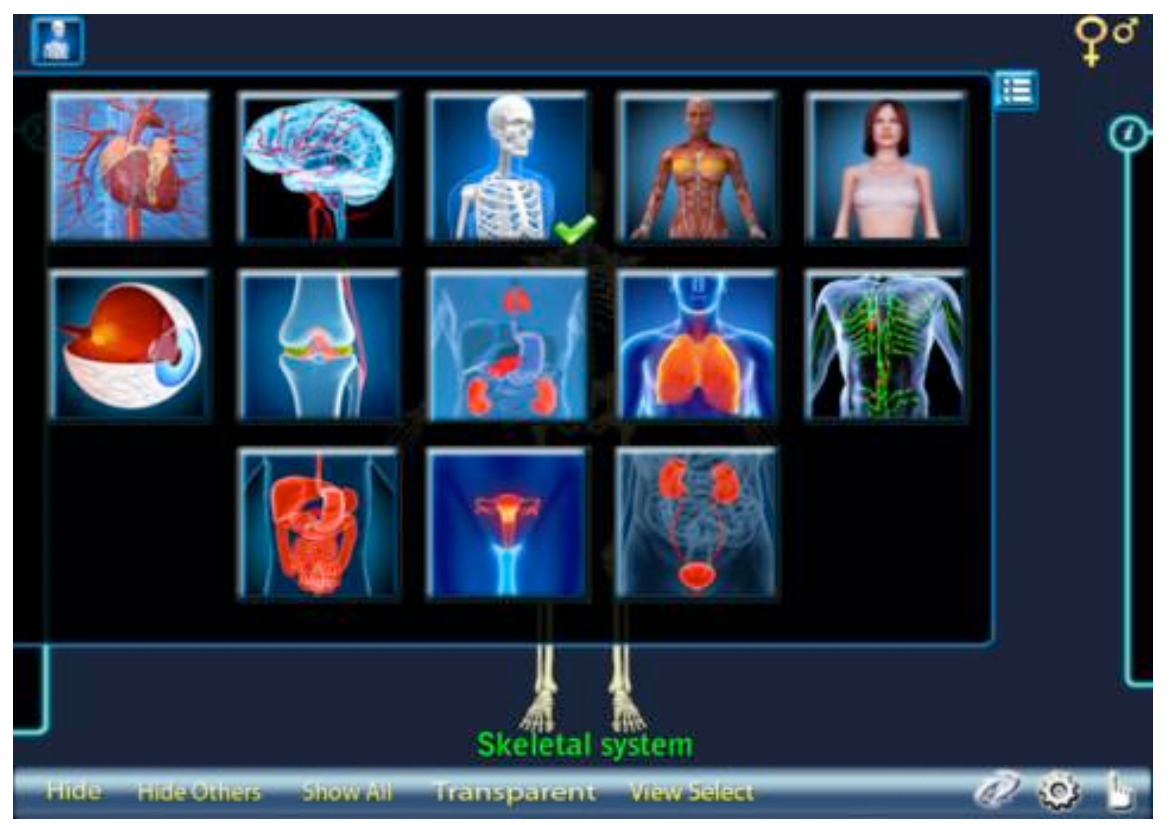

Fig. 3. Screenshot of an interface of 3Dbody

\section{Construction of 3DBody software experimental platform based on action-orientated approach}

The construction of a software platform requires the following steps, including requirement analysis, software development via overall design, detailed design, and 
coding, software verification in testing environment, launching for operation, and later maintenance for stable development.

\subsection{Requirement analysis}

Requirement analysis is the first step for constructing a software platform. Only by detailed analysis of requirements, we can learn about the required basic functions of software. The system designed in this paper is required to meet the requirements of the flow of action-orientated teaching, interactive teaching mode and unified teaching software, as follows.

1. Access control. The software should be designed to support administration of multiple roles, namely consisting of administrator mode, teacher mode and student mode. Different roles can view different contents according to the authority information granted to them. For example, the administrator can maintain and view the basic information of all teachers and students, teacher can view the scores and assignment information of his/her students, and students can view their own learning contents, assignments, and scores.

2. Multi-platform compatibility. Different devices have their own advantages. This software should be designed to meet students' needs of acquiring basic knowledge and making instant communication. Thus, this software should be developed to be of multi-platform compatibility. According to a survey on student equipment on the market, the software should be compatible with Windows, Android and IOS at least.

3. Data support. It needs to update the learning materials on the software platform regularly, including basic courseware and extra-curricular materials. Hence, this system should be designed to support both active and passive updating of software data. Active updating means that user actively updates data online, and passive updating means that the materials recommended by teachers to students will be automatically downloaded into students' equipment. Since students usually employ different devices at different times, information synchronization should be realized among different devices, to avoid data loss, and ensure that user can view the latest data via any terminal at any time.

4. The organizational form of the software should meet the requirements of actionorientated learning, to turn point-type knowledge points into net-type knowledge points so that students can form a solid theoretic reserve before implementation.

5. This software should be designed to provide multiple data presentation modes to stimulate students' reading interest, and multiple input and output modes to facilitate communication, such as speech input, real-time voice conversation, video call, multimedia picture, video uploading, and text conversation, so as to provide multiple modes for student-student interaction and student-teacher interaction and serve the action-orientated teaching method to the largest extent. 


\subsection{Architecture design}

Based on the requirement analysis of the system, the architecture diagram of this system designed in this paper is as shown in Fig. 4. This system is constructed based on MVC framework. Thus, the system is divided into three layers, namely user interface, database and business logic. User interface is for receiving user input and presenting results to user, database is for storing data, and business logic layer is for calling different business processing modules according to user instructions. The user interface transfers data to the business logic layer after receiving user input. The business processing module processes the data in the database, and returns the results to the user interface for display. By the function, the business logic layer consists of data processing module, man-machine interaction module and interaction module. The data processing module is mainly for data circulating, specifically including data downloading, data updating and data transmission. The man-machine interaction module is mainly for handling the links of user-software interaction, including user instruction receiving, performing statistics and inquiry according to user instructions, and result returning, and so on. The interaction module is mainly for handling useruser interaction. User-user interaction is mainly realized by means of real-time voice conversation, real-time video conversation, and time-lapse text conversation. Please see Fig. 4 for the architecture diagram of the system.
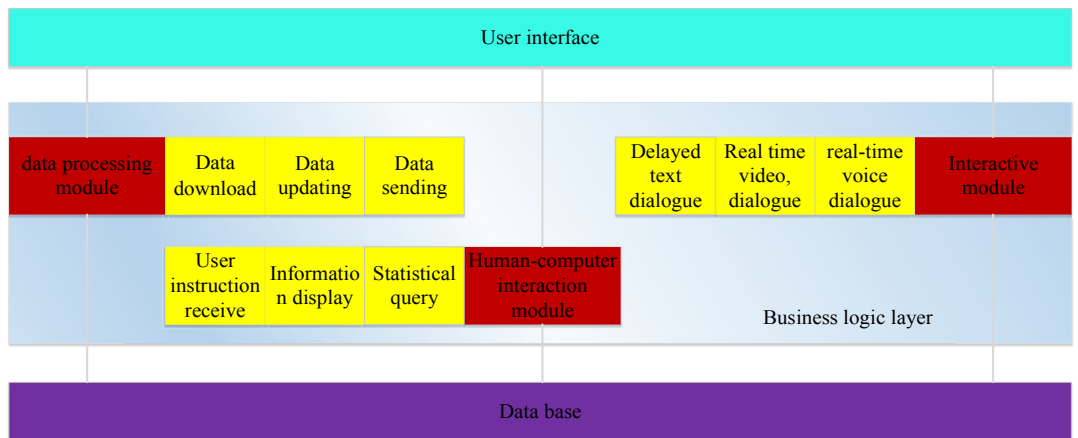

Fig. 4. System architecture diagram

As shown in the system architecture diagram of the software, different logic modules are presented. It is good for avoiding repeated code development by developing each module separately, to increase the utilization ratio of code. From the aspect of function, an application framework as shown in Fig. 4-2 of this software can be developed. The software has three functions, namely essential data learning, actionorientated approach association and independent practice. Essential data learning consists of four modules, namely theoretical knowledge learning, teaching video, knowledge review and simulation test. Action-orientated approach association consists of three modules, namely grouping, plan making, and interaction module. Independent practice consists of three modules, namely game module, question module, and difficulty review. Please see Fig. 5 for the application framework of the 3DBody software. 


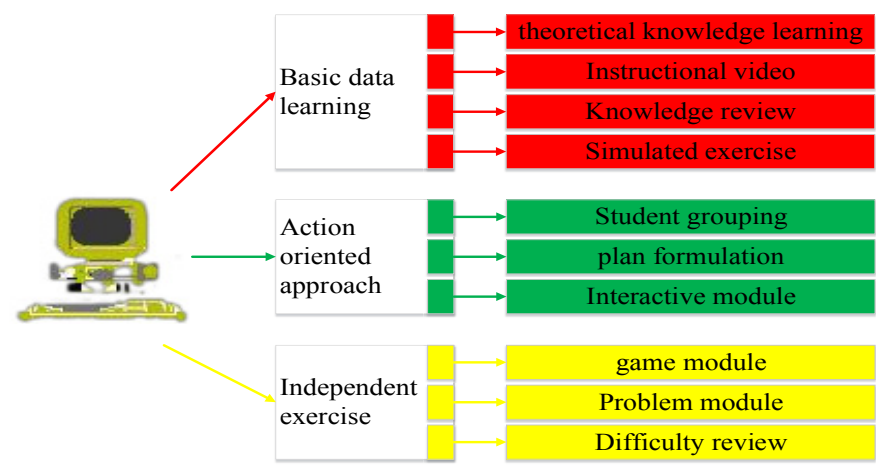

Fig. 5. Application framework of 3DBody software

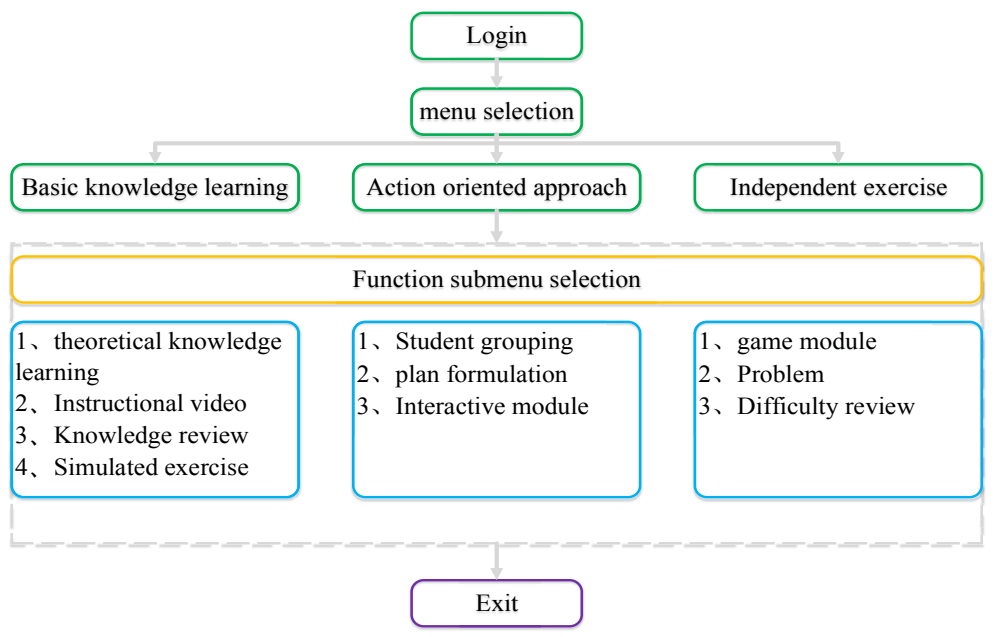

Fig. 6. Functional diagram of 3DBody software experimental platform

\subsection{Function display}

The functional diagram of the 3DBody software experimental platform based on action-orientated approach designed in this paper is as shown in Fig. 6.

According to the principle of access control, three roles are designed for this system, namely administrator, teacher and student, and each role can have an access to specific data. The administrator mode is mainly for role assignment, authority management, and management of administrative functions of the system, to ensure that teacher users and student users can use the software smoothly. The teacher mode is mainly for designating learning contents, examining student plan, importing teaching video, interacting with students, and reading and commenting on assignment and test paper. The student mode is the core of the system, and also the focal point of this paper. In the student mode, student users can visit the desired theoretical knowledge, watch teaching video, select a group, participate in group plan making, and view their 
assignment and test performance. Student user cannot inquiry the scores of other student users, and teacher user also cannot view the scores and assignment information of students of other teacher users.

The first step of using the software is to log in with user ID and password. For the first login, user needs to apply to the administrator for the login right to obtain the initial password. In the case that user logs in the system via different platforms, the system will automatically call backend data to realize data synchronization among different platforms. Student user can see the main function menu after entering the system, of which the options include basic knowledge learning (for students to learn theoretical knowledge), action-orientated approach association (for students to form group, make plan and launch real-time or time-lapse discussion); and independent practice module (for students to consolidate knowledge).

(1) The function sub-menu as shown in Fig. 7 will present if user click the option of basic knowledge learning, of which the options include digestive system, respiratory system, urinary system, etc. Different sub-functions will be presented if user click different options, and user can elect to handle different learning tasks by choosing different options. For theoretical knowledge learning, multiple data presentation modes are provided, including slides of knowledge points, pictures of anatomical specimen, videos about field application of anatomical specimen. Teaching videos refer to videos recording classroom teaching uploaded by teacher users after each class, which are provided to help students make up the deficiencies. The knowledge review module is for underlining key points of the learned knowledge points and the knowledge points to be applied in practice. The simulation test link will generate simulation test papers by choosing questions from the question bank according to the learned theoretical knowledge to help students evaluate their learning condition. Alternatively, teacher user can push test paper via this link, to realize teacher evaluation.

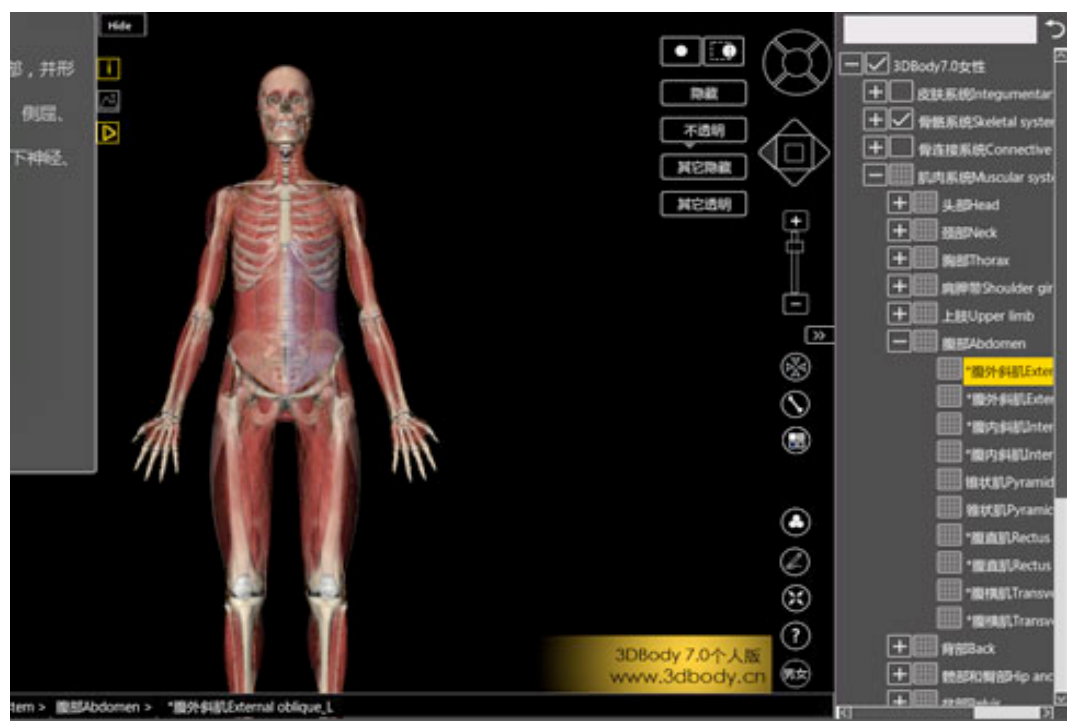

Fig. 7. Screenshot of working page of 3DBody software experimental platform 
(2) By selecting the option of action-orientated approach association, user can see a function sub-menu consisting of the following options such as student grouping, plan making and interaction module. This link is mainly for realizing grouping for actionorientated teaching. Student user should select a group and make a group plan first, and teacher user will log in the system to examine and approve the plan. The interaction module is provided with three modes, namely video call, voice communication and text conversation, with which student user can communicate with teacher user or other group members. The interaction module also has the function of sound and video recording, with which student user can record conversations in the case that it is hard to take notes.

By selecting the option of independent practice, user can see a function sub-menu, of which the options include game module, question module, and difficulty review. This link is mainly for helping student user consolidate knowledge. The game module is designed based on the theoretical knowledge, for which a rule of fighting one's way through a difficult pass applies. Via the question module, student user can raise questions, and student user or teacher user can answer the questions. With the module of difficulty review, student user can review the difficult knowledge points underlined in the link of independent practice, to strengthen memory. Fig. 8 shows interface of independent practice module of 3DBody software experimental platform.

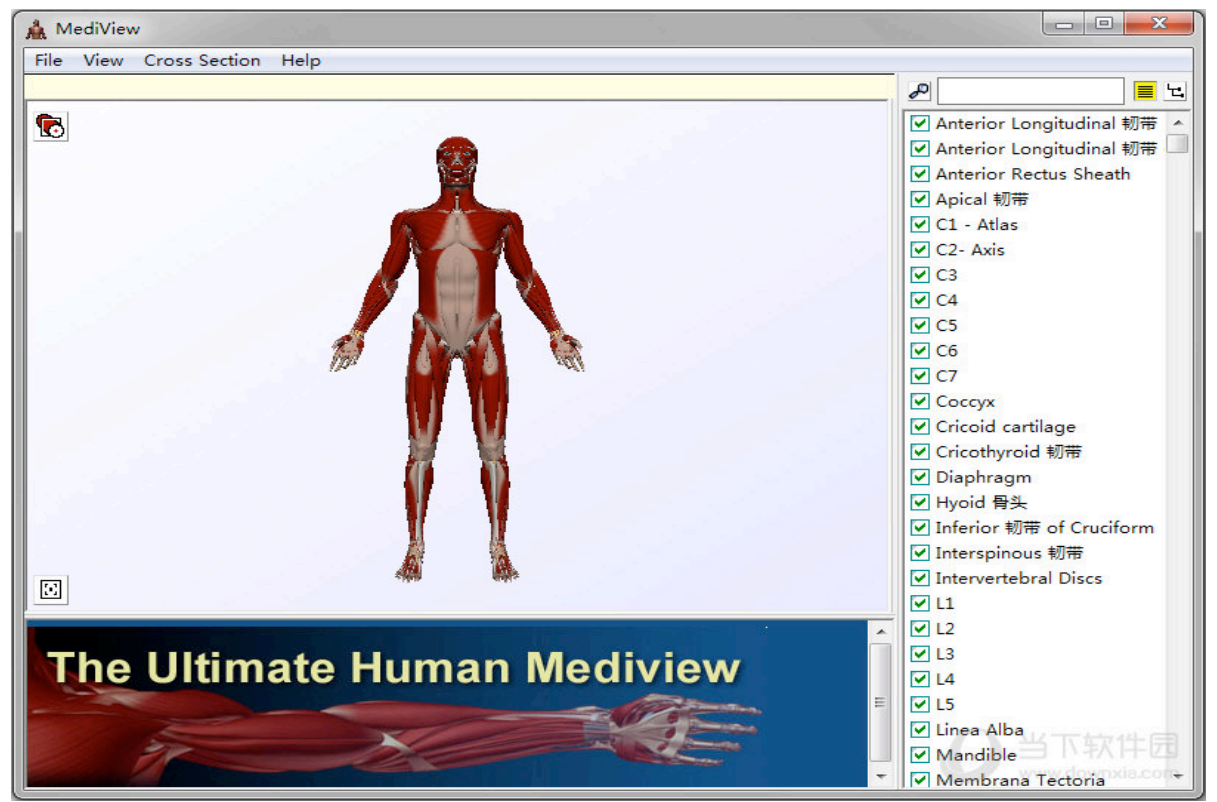

Fig. 8. Screenshot of interface of independent practice module of 3DBody software experimental platform

(3) User needs to log out the system if he/she wants to stop accessing to the system, for fear of privacy disclosure. In this way, it can be ensured that the established study plan will not be modified by others. 


\subsection{Effect check}

For purpose of this paper, a contrast experiment is designed to verify the teaching effect and effectiveness of the new-type experimental software platform based on action-orientated approach. For this paper, the course of Sports Anatomy was taken for experiment, and the freshmen of the specialty physical education of a university in Hunan province were surveyed. Two classes were taken as the experimental group at random, and another two classes as the control group (for which traditional teaching method was implemented). At the end of a semester, a survey was made on the comments of the students of the four classes on the effect of the software in the form of questionnaire, and the result is as shown in Tab. 1. The situations of the students of the two groups of grasping skills were compared by means of result statistics, and the result is as shown in Tab.2. For purpose of evaluation, the average scores were calculated out.

According to Tab. 1, the students are more satisfied with the new-type experimental platform than with the traditional teaching method, because the former is designed to realize the idea of student-centered, and help students give full play to their initiative, to become the leading role in learning rather than the passive knowledge receiver in traditional classroom teaching.

According to Tab. 2, the two groups appeared to be equally matched in the exam in the 1st month, but the experimental group had been being superior to the control group since the 2 nd month. This is because that the students need a period to adapt to the new teaching method. It is thus clear that the students of the experimental group had got used to the new-type experimental platform within one month, so that they could surpass the control group. This is thanks to the advantages of the experimental platform. This experimental platform focuses more on the integration of theory with practice. At this platform, students don't have to learn by rote and mechanically apply knowledge points. Instead, the combination of theory with practice of anatomy is truly realized via the platform, which can help students develop profound understanding. Besides, teaching method available at the experimental platform is subject to updating from time to time, so that it can address students' all needs of course learning alone, and help students consolidate difficult knowledge points. Thus, the experimental group performed significantly better than the control group did.

Table 1. Students' comment on effect of the software

\begin{tabular}{|l|c|c|c|c|}
\hline \multicolumn{1}{|c|}{ Group } & Class performance & Skill training & Ability training & Total score \\
\hline Experimental group & 30.25 & 32.55 & 31.80 & 94.6 \\
\hline Control group & 28.95 & 31.23 & 30.2 & 90.38 \\
\hline
\end{tabular}

Table 2. Evaluation on students' theoretical knowledge and skills

\begin{tabular}{|l|c|c|c|c|}
\hline \multicolumn{1}{|c|}{ Group } & $\mathbf{1}^{\text {st }}$ month & $\mathbf{2}^{\text {nd }}$ month & $\mathbf{3}^{\text {rd }}$ month & Final exam \\
\hline Experimental group & 90.31 & 91.28 & 88.24 & 92.1 \\
\hline Control group & 91.54 & 90.65 & 87.11 & 90.00 \\
\hline
\end{tabular}




\section{Conclusions}

In this paper, a new-type experimental software platform based on actionorientated approach is designed and implemented, for which MVC framework technology and 3DBody teaching software are adopted. The platform has been applied in experimental teaching of the course of Sports Anatomy. The survey on students and evaluation of students' performance at the end of a semester show that students are satisfied with the new-type experimental platform designed in this paper, because it is helpful to improve students' practical skill and ability and arouse students' subjective initiative in learning.

To sum up, the practice of utilizing information computer technology to add learning has been gradually accepted and adopted by the public in modern times when the information technology develops rapidly, and various virtual teaching software are attracting more and more attention and have been adopted by educators of different subjects. Via the attempt of applying the 3DBody experimental software platform in teaching of the course of Sports Anatomy, we realize that 3D virtual teaching technology can largely promote teaching practice, and provides a new idea and direction of educational reform to us.

\section{Acknowledgment}

A Project Supported by Scientific Research Fund of Hunan Provincial Education Department (17B058).

\section{$7 \quad$ References}

[1] Granmo, M., Bengtsson, F. Teaching Anatomy in the Multimedia World - Using Digital Tools for Progressive Learning over Time. Creative Education, 2015, vol. 6(11), pp. 11931200. https://doi.org/10.4236/ce.2015.611117

[2] Nian, X.L. Application of action oriented teaching method in computer teaching reform. Education and Vocation, 2015, vol. 15, pp. 88-90.

[3] Brenton, H., Hernandez, J., Bello, F., et al. Using multimedia and Web3D to enhance anatomy teaching. Computers \& Education, 2007, vol. 49(1), pp. 32-53. https://doi.org/10.1016/j.compedu.2005.06.005

[4] Stirling, A., Birt, J. An enriched multimedia eBook application to facilitate learning of anatomy. Anatomical Sciences Education, 2014, vol. 7(1), pp. 19-27. https://doi.org/10.1002/ase.1373

[5] Saltarelli, A.J., Roseth, C.J., Saltarelli, W.A. Human cadavers Vs. multimedia simulation: A study of student learning in anatomy. Anatomical Sciences Education, 2014, vol. 7(5), pp. 331-339. https://doi.org/10.1002/ase.1429

[6] Zhou, H.L. Combining flash animation with the teaching of sports anatomy PBL. Science \& Technology Information, 2009, vol. 17, pp. 162-162.

[7] Song, Y., Liu, Y., Zhang, X. Research on the Inquiry System of Showroom Multimedia of Sports Anatomy. Ieri Procedia, 2012, vol. 2, pp. 183-187. https://doi.org/10.1016/j.ieri. 2012.06.072 
[8] Yi, K.G., Li, F.Q., Peng, Y. Action-oriented Teaching Method in Applied Practice Courses:Paradigm Shift and Countermeasures. Journal of Ningbo University (Educational Science Edition), 2016, vol. 38(2), pp. 88-92.

[9] Veragarcia, F.J., Moreside, J.M., Mcgill, S.M. MVC techniques to normalize trunk muscle EMG in healthy women. Journal of Electromyography \& Kinesiology, 2010, vol. 20(1), pp. 10-16. https://doi.org/10.1016/j.jelekin.2009.03.010

[10] Sun, D.Z., Zhang, Z.G., Sun, Z.S. Application of Visible Body (3D) software in anatomy teaching. Progress of Anatomical Sciences, 2014, vol. 6, pp. 598-598.

\section{Authors}

Yujia Ren is an associate professor in the Physical Education Institute, Hunan First Normal University, Changsha 410205, Hunan, China (renyujia@163.com).

Xia Jiang is an associate chief physician in the Wuhan Sports University, Wuhan 430079, China(274541977@qq.com).

Siyuan Tang (Corresponding Author) is a professor in the Nursing School, Central South University, Changsha 410013, Hunan, China (1186224696@qq.com).

Article submitted 16 May 2017. Published as resubmitted by the authors 17 July 2017. 